\title{
In Vitro HIV-1 Selective Integration into the Target Sequence and decoy-effect of the modified sequence
}

\author{
Tatsuaki Tsuruyama \\ From Frontiers of Retrovirology 2011 \\ Amsterdam, The Netherlands. 3-5 October 2011
}

\section{Background}

There have been a few reports that the HIV-1 genome can be selectively integrated into the genomic DNA of host cell. However, actual target sequence of integration has not been reported. The target sequence within the second intron of Stat $5 a$ gene of MLV integration has been already reported by us [1,2] (Patent No. 4631084, 2010, Japan, W02006/022249).

\section{Materials and methods}

On basis of the CA-rich sequence motif that was observed in MLV integration target sequence, we prepared a substrate repeat sequence DNA for in vitro HIV-1 integration, 5'-(GTCCCTTCCCAGT)6(ACTGGGAAGGGAC)6-3' and a set of modified sequence DNAs by deletion of CAGT in the repeat unit. This $C A G T$ and ACTG (shown in italics in the above sequence) in the repeat units originated from the HIV-1 proviral genome ends. We devised in vitro integration by using these sequence DNAs, HIV-1 provirus DNA, and recombinant HIV-1 integrase.

\section{Results}

In vitro integration occurred at the target sequence DNA at significant higher frequency and selectivity in comparison to random-sequence DNAs. Although the target sequence consisted of repeat segments, in vitro integration selectively occurred in the middle segment of the repeat sequence. On the other hand, both frequency and selectivity decreased markedly when using sequences with deletion of CAGT in the middle segment of the target sequence. Moreover, on incubation with

Department of Pathology, Graduate School of Medicine, Kyoto University, Kyoto city, Kyoto Prefecture, Japan the CAGT-deleted DNAs and target sequence, the integration efficiency and selectivity for the target sequence were significantly reduced. This interesting data indicated interference effects by the mixed sequence $C A G T$ deleted DNAs. Besides, efficiency and selectivity of integration into the target repeat sequence was found to vary discontinuously with changes in manganese dichloride concentration in the reaction buffer for in vitro integration. Because the structure transition at the critical concentration was exclusively observed in the target sequence DNA by electrophoresis, these discontinuous changes in in vitro integration were probably due to fluctuation in the secondary structure of the target DNA segment. Such structural isomers may be favorable for selective integration into the target sequence DNA.

\section{Conclusions}

There is a considerable selectivity in in vitro HIV-integration into the specified sequence. Similar DNA sequences can interfere with the process of selective integration. Dependency of in vitro integration upon the secondary structure of the target DNA is one of the models of in vivo integration that is promoted by open chromatin structure that is induced by transcriptional factor bound to the neighboring DNA segment. In addition, the present in vitro integration system can be useful for monitoring the integration activity or test of integrase inhibitor [3].

\section{Published: 3 October 2011}

\section{References}

1. Tsuruyama T, Nakamura T, Jin G, Ozeki M, Yamada Y, Hiai H: Constitutive activation of Stat5a by retrovirus integration in early pre-B lymphomas

\section{C)


of SL/Kh strain mice. Proceedings of the National Academy of Sciences of the United States of America 2002, 99:8253-8258.

2. Tsuruyama T, Hiratsuka T, Jin G, Imai Y, Takeuchi H, Maruyama Y, Kanaya K, Ozeki M, Takakuwa T, Haga $\mathrm{H}$, et al: Murine leukemia retrovirus integration induces the formation of transcription factor complexes on palindromic sequences in the signal transducer and activator of transcription factor 5 a gene during the development of pre-B lymphomagenesis. Am J Pathol 2011, 178:1374-1386.

3. Tsuruyama T, Nakai T, Hiratsuka T, Jin G, Nakamura T, Yoshikawa K: In vitro HIV-1 selective integration into the target sequence and decoy-effect of the modified sequence. PLoS One 2010, 5:e13841.

doi:10.1186/1742-4690-8-S2-P85

Cite this article as: Tsuruyama: In Vitro HIV-1 Selective Integration into

the Target Sequence and decoy-effect of the modified sequence.

Retrovirology 2011 8(Suppl 2):P85.

\section{Submit your next manuscript to BioMed Central} and take full advantage of:

- Convenient online submission

- Thorough peer review

- No space constraints or color figure charges

- Immediate publication on acceptance

- Inclusion in PubMed, CAS, Scopus and Google Scholar

- Research which is freely available for redistribution

Submit your manuscript at www.biomedcentral.com/submit 